\title{
Exploring the Promotion Path of Urban Reading from the Perspective of Urban Cultural Soft Power
}

\author{
Youyou Jiang* \\ Chongqing City Management College, Chongqing 401331, China \\ *Corresponding author: Youyou Jiang, 154245945@qq.com
}

\begin{abstract}
As a form of urban culture, urban reading plays an important role in the improvement of the citizens' quality, urban quality, and urban spirit. In the new era, there are imbalances in the supply and demand, content construction, regional structure, and ecological structure of urban reading. It is necessary to analyze and grasp its development trend, optimize the development path of urban reading, and promote the improvement of urban cultural soft power.
\end{abstract}

Keywords: Cultural soft power; Urban reading; Urban culture

Publication date: December 2021; Online publication: December 23, 2021

\section{Introduction}

Urban reading developed from national reading, and national reading evolved from the World Reading Day. National reading refers to the activities that involve people using language to gather information, understand the world, develop thinking, and gain aesthetic experience. On the other hand, urban reading refers to the activities that involve the citizens using language to gather information, understand the world, develop thinking, and gain aesthetic experience. In 1995, the United Nations Educational, Scientific, and Cultural Organization (UNESCO) officially declared April 23 as World Reading Day. China has been promoting the national reading campaign since 2006, and by 2020, the reading rate of adult citizens in China, including books, newspapers, and digital publications, increased to $81.3 \%$ from $48.7 \%$ in 2006 . It has become the largest brand reading activity of World Book Day.

\section{Role of urban reading in improving the soft power of urban culture}

Urban reading is an indispensable part of the development of urban cultural soft power. It plays an important role in urban cultural construction and an inestimable role in the overall improvement of the citizens' quality, urban quality, and urban spirit.

\subsection{Improving the quality of citizens}

The reading ability and reading level of the citizens largely reflect their quality and determine the overall creativity as well as development potential of a nation or region. For the general public, effective reading is an important way to update their knowledge and improve their quality from all aspects. Reading directly affects their growth in ability, their positions in workplace, and their roles in the society.

\subsection{Shaping the urban spirit}

Urban reading is closely related to urban cohesion and a sense of belonging among the citizens. According to the 2016-2017 National Reading Data, released by the Beijing Municipal Bureau of Press, Publication, 
Radio, Film, and Television, the reading rate in Beijing $(92.73 \%)$ is at the national leading level, highlighting the "leader" position of the national cultural center ${ }^{[2]}$. Under this positive reading atmosphere, it encourages more people to consciously join the reading team. In that way, they would be able to actively explore and innovate ideologically, organizationally, and systematically, learn how to share the achievements of innovation and development with people, and then guide the forces of the society to unite and serve in the shaping of the urban spirit.

\subsection{Upgrading the urban quality}

Urban reading can continuously improve the quality of a city and cultivate its temperament. According to the Urban Temperament from Reading Index report, released by Guangming Daily, cities with strong reading ability such as Beijing, Shanghai, Shenzhen, Guangzhou, and Chengdu can deploy as well as intervene in advance in terms of overall planning, which involves urban planning, economic development, and cultural construction ${ }^{[3]}$. Cities with strong reading ability can improve their position, focus on the development direction, target "high quality" as their goal, and comprehensively promote urban quality construction as well as high-quality development.

\section{Evaluating the structural problems of urban reading in the new era}

In the new era, the reading activities in cities and provinces are more three-dimensional and diversified; in addition, the national reading index is gradually improving. At present, there are still many problems and deficiencies in regard to deepening the promotion of urban reading and comprehensively improving the soft power of urban culture. It is urgent to carefully examine the structural problems of urban reading in the new era from an overall perspective ${ }^{[4]}$.

\subsection{Structural defects of urban reading supply and demand}

The cultural needs of urban residents continue to increase. At present, the per capita number of public resources, such as libraries, is seriously insufficient, thereby facing the difficulty in meeting the actual needs of the residents. According to data, from 2013 to the first half of 2021, China's per capita cultural consumption increased from 576.7 yuan to 1,119 yuan, with a growth rate of $94.04 \%$. In recent years, cultural consumption has become a new hot spot under the category of people's consumption. In sharp contrast, urban libraries and other public resources are extremely tight, which does not match the growing cultural needs. According to the International Federation of Library Associations and Institutions (IFLA), there is a public library for every 40,000 people. According to data, in 2016 , the ratio of public libraries to the number of people in China is 1 to 460,000 people.

\subsection{The structural lack of urban reading content construction}

First, the problem of the "hardware is too hard, and software is too soft" is prominent. Some cities focus on building large and comprehensive libraries and museums, neglecting the connotation construction of operation, service, product, and innovation of urban reading. This is generally reflected in the short board of cultural element investment, low level and efficiency of intelligent service, relatively aging supply structure, insufficient integration of cultural resources, etc. Second, it believes in following the "doctrine"; therefore, it lacks characteristics and innovation. There are only a few high-quality cultural and creative products in urban museums, memorial halls, and other reading spaces. The variety of cultural and creative products is relatively single, lacking in-depth excavation and interpretation of their own characteristic cultural resources. They are only simple imitations with insufficient innovation. Third, there are hardly any cultural and creative talents, and the structural shortage is prominent. The structure of cultural and creative 
talents is unreasonable, especially the lack of high-level urban reading space planning and creative product research and development (R\&D) talents as well as experienced and high-quality compound talents integrating urban reading space development and operation, planning and promotion, as well as innovation and management.

\subsection{Structural imbalance of urban reading areas}

It is mainly reflected in the imbalance between the east, the middle, and the west, the imbalance between developed and underdeveloped areas as well as between urban and rural areas. According to the data from China Statistical Yearbook 2020 by the National Bureau of Statistics, there are 3,212 public libraries in China, with a total collection of nearly 1 billion books, and the per capita public book volume is 0.7 , of which the per capita public book volume is up to 3.21 in Shanghai. The cultural infrastructure, resource allocation, and spatial layout of eastern or developed cities are far better than those of western or underdeveloped cities.

\subsection{Structural imbalance of urban reading ecology}

Modern technologies such as network technology and mobile terminals have greatly changed the mode of reading. Jumping and incomprehensible shallow reading has become a label of urban reading. Urban reading is increasingly mobile and fragmented. With the increasing development of mobile network technology, the internet is moving, and urban reading has also entered the stage of "mobility + reading." According to the Research Report on China's Urban Reading Index in 2021, the number of people reading through mobile terminals has been rising since the first half of 2021. "Shallow reading" is becoming more and more popular. Represented by microblogs and circle of friends, the new social and sharing reading mode is becoming more popular among the general public.

\section{Optimizing the development path of urban reading and boosting the improvement of urban cultural soft power}

The development of a city needs distinctive culture, inside information, and connotation. It needs to innovate and optimize the development path of urban reading, strive to create a cultural card of urban reading, enable reading to ensure urban construction and development, as well as cultivate the urban spirit and temperament.

\subsection{Deepening the reform of the supply side of public cultural products and effectively expand the supply}

First, it is important to break the traditional pattern of fragmentation, regional closure, and urban-rural separation, as well as make every effort to promote the large-scale industrialization of diversified cultural services and creative products. Second, it is essential to guide and encourage the participation of social capital or forces and encourage the adoption of public private partnership (PPP) urban reading project cooperation mode to expand the cultural industry. Third, a long-term promotion mechanism of cultural consumption should be built. The macro data and micro samples of cultural consumption should be deeply explored, and a more scientific and reasonable cultural consumption policy should be established.

\subsection{Strengthening the positioning of cultural function and realizing the development of different characteristics based on regional resource endowment}

Taking into consideration of one's own development reality, it is necessary to investigate the reading 
resources, market scale, facility construction, and other basic conditions of the city, analyze the main problems, comprehensively consider the shortcomings, accurately grasp the direction, objectives, and priorities of the reading development of the local city, study and formulate the plan in line with the local development needs, fully tap the comparative advantages, as well as realize the dislocation development. For example, relatively small cities have inherent advantages of large resources, good ecology, and low cost. They take the initiative to undertake the spillover links of the cultural industry in big cities, become the satellite belt of the cultural industry in big cities, specialize, refine, deepen, and optimize the downstream, as well as create the "little giant" of the industry.

\subsection{Highlighting the integration of resources, refining the classification and grading of reading, as well as stimulating the creation of urban culture}

On the one hand, it is important to strengthen resource integration and promote the optimization as well as upgrading of urban reading. Focusing on the optimization and integration of various forms of urban reading carriers would help realize the sharing of resources and information. On the other hand, reading resources and groups should be classified and graded. According to different ages, reading resources can be divided into childhood, youth, middle-aged, and elderly; under the category of quality, reading resources can be divided into classic reading and regular reading.

\subsection{Relying on information and interactive ways to establish an excellent urban reading platform}

First, special action plans such as urban reading and building a high-quality urban reading project should be carried out. Cultural programs such as traditional reading should be held, and the organic integration of traditional reading and new reading should be promoted. Second, the function of urban reading platforms should be strengthened, the formulation of a "menu" reading catalogue list should be sped up, and door-todoor book delivery services should be offered, so that citizens can easily obtain the books they need. Three, urban reading platforms should introduce modern information technology, actively develop mobile applications, official accounts, etc. to further transform the soft power of city culture into hard power.

\subsection{Strengthening the innovation of the system and mechanism as well as consolidating the competitiveness of urban culture}

First, the construction of urban reading service carriers should be innovated in such a way that it focuses on building a cultural complex integrating theme lectures, cultural salons, cultural forums, interactive exchanges, reading, and speaking. This includes digging into the service functions of public libraries and 24-hour study carriers, extending the ideological tentacles of urban reading carriers, as well as giving full play to their influence. Second, an urban reading development community should be built to share and build one another to achieve win-win results. It is necessary to be problem oriented, learn from good experiences and good practices of neighboring provinces and cities, as well as jointly build and share urban reading cloud platforms.

\section{Funding}

This study was supported by the Humanities and Social Sciences Project of Chongqing Education Commission (Item Number: 21SKSZ092).

\section{Disclosure statement}

The author declares that there is no conflict of interest. 


\section{References}

[1] National Press and Publication Administration, 2021, Release of the Results of the 18th National Reading Survey. Beijing Public Network Security, April 26, 2021. http://www.nppa.gov.cn/nppa/conte nts/280/75981.shtml

[2] Liu K, 2019, China's Cultural Consumption Market Has Broad Prospects. Guangming Daily, June 20, 2019.

[3] Li Q, 2011, Study on Reading Frequency and Its Influencing Factors of Urban Population in China. Library Magazine, 2011(06).

[4] Yi T, 2014, Quantitative Analysis and Research Suggestions of National Reading Research in China. Library and Information Knowledge, 2014(11). 